\title{
CARTAS AO EDITOR
}

\section{Triagem neonatal de fibrose cística}

A publicação do artigo "Controvérsias na fibrose cística - do pediatra ao especialista" subscrito por Ribeiro e col. aguçou-me o interesse em discutir algumas "controvérsias" relativas à triagem neonatal da enfermidade ${ }^{1}$.

$\mathrm{Na}$ realidade, controvérsias não são raras na prática médica. Caso contrário, há muito o antigo provérbio "em Medicina, a verdade de hoje será a mentira do amanhã" já teria sido sepultado.

Saliento que a história da fibrose cística remonta ao ano de 1650, com a descrição das primeiras observações clínicas da enfermidade. Inclusive, na Europa, o anedotário folclórico consagrara a referência de que "as parteiras bateriam na fronte dos recém-nascidos e, se o suor fosse anormalmente salgado, esses recém-nascidos estariam fadados à morte por congestão pulmonar crônica e suas consequiências"2.

Abordar as controvérsias da triagem neonatal para a fibrose cística relembra-me o início do screening da fenilcetonúria nos primórdios da década de 60 , graças ao trabalho pioneiro do Dr. Robert Guthrie, com o Inhibition Assay Test $^{3}$. Seus esforços, entretanto, tiveram na época a oposição da American Academy of Pediatrics e de outras tantas sociedades médicas, como de muitos pesquisadores no campo do metabolismo humano. Por múltiplas razões, acreditavam prematuro obrigar a cada recém-nascido ser avaliado para a PKU, e objeções intensificaram-se durante os primórdios dos programas de screening.

Existiram vozes céticas - algumas ruidosas, outras menos candentes. Um conjunto mais estrito de questões ampliou o foco da discussão. Questões como as da sensibilidade e especificidade do teste de Guthrie.

No artigo em epígrafe, Ribeiro e col. são categóricos ao afirmar que "a realização da triagem neonatal na população em geral é controversa, envolve complexas questões sociais, culturais, política de saúde, éticas e emocionais" ${ }^{1}$.

Aliás, essa controvérsia respalda-se na posição da Task Force on Neonatal Screeening da AAP, que se posicionou, em 1983, contra a introdução de novos programas oficiais de screening até a confirmação da validade da triagem neonatal para a fibrose cística e a avaliação dos benefícios e eventuais riscos ${ }^{4}$.
Na realidade, é pertinente a preocupação em relação às consequiências dos resultados falso-positivos como causa de ansiedade dos pais, capaz de confundi-los a respeito do risco dos filhos em desenvolverem a fibrose cística, após uma triagem falso-positiva e, inclusive, desencorajá-los sobre futuras gestações.

Controvérsias à parte, é lógico o raciocínio em não se restringir a triagem neonatal, pois significará excluir tantas outras crianças do diagnóstico precoce da enfermidade e incluí-las no grande grupo daquelas que ultrapassam os dois ou três anos de idade à margem do diagnóstico clínico. Aliás, outra não é a expectativa de Rozov e col. quanto às crianças brasileiras, diagnosticadas em média com a idade de 3,8 anos, e que defendem o screening como medida capaz de antecipar a época do diagnóstico e melhorar o prognóstico da fibrose cística ${ }^{5}$.

Assim, as "controvérsias" mantêm-se abertas aos debates, embora vários estados americanos, a Austrália e o Reino Unido tenham implantado o screening em programas oficiais.

Observações clínicas na última década são sugestivas quanto aos resultados favoráveis da triagem neonatal para a fibrose cística. Especialmente em relação aos déficits nutricionais, identificação e tratamento precoces da enfermidade pancreática, diminuição da morbimortalidade e do número de internações hospitalares nos dois primeiros anos de vida.

Com a implantação no Brasil, do teste do pezinho ampliado, incluindo a fibrose cística, tenho a convicção de que as "controvérsias entre pediatras e especialistas" serão esclarecidas, a não ser que pretendamos retroagir ao ano de 1650, quando, segundo o anedotário folclórico europeu, reservava-se o diagnóstico da fibrose cística às "parteiras"2. Na realidade, a disponibilidade do teste do pezinho ampliado transcende as "controvérsias entre pediatras e especialistas". Respalda-se, indiscutivelmente, com todas as implicações legais, no Estatuto da Criança e do Adolescente (Lei Federal 8.069, art. $10^{\circ}$ ).

Inquestionavelmente, salvo as dúvidas relativas às reações dos pais, os custos oficiais e, sobretudo, o bem-estar das crianças, os resultados mais significativos da evolução do tratamento da fibrose cística referem-se à maior expectativa de sobrevida dos pacientes. Em meu entender, corolário da conjugação de fatores como os avanços no conhecimento da enfermidade, as maiores possibilidades do diagnóstico precoce e a rotina do tratamento em centros especializados 6 . 


\section{Referências bibliográficas}

1. Ribeiro JD, Ribeiro MO, Ribeiro AF. Controvérsias na fibrose cística. J Pediatr (Rio J) 2002; 78:S171-S186.

2. Taussig LM. Cystic fibrosis: An overeview. In: Taussig LM, ed. Cystic fibrosis. New York: Thieme-Stration; 1984.p.1-9.

3. Guthrie R, Susi, A. A simple phenylalanine method for detection phenylketonuria in large populations of newborn infants. Pediatrics 1963; 32:338.

4. American Academy of Pediatrics. Task Force on Neonatal paper. Pediatrics 1983; 72:741-45.

5. Rozov T, Guimarães B, Zullo M, Cardieri J, Nakaie C. Clinical experience of a cystic fibrosis center. International Symposium on Inborn Errors of Metabolism. São Paulo. 1989.

6. Mahadeva R, Web K, Westerbeck RC, et al. Clinical outcome in relation to care in centers specializing in cystic fibrosis: cross sectional study. BMJ 1998;316:1771-5.

\section{Luiz Carlos Esperon}

Doutor em Medicina e ex-Professor Titular de Pediatria do Curso de Medicina da URG

\section{Resposta dos autores}

Nós agradecemos o interesse e os comentários do Dr. Luiz Carlos Esperon sobre as controvérsias da triagem neonatal na fibrose cística (FC).

Quando se pesquisa no Medline sobre Neonatal screening for Cystic Fibrosis, encontram-se 240 artigos, sendo 120 até 1996, e 120 após. Portanto, após 1996 foram publicados em média 20 artigos por ano sobre esse assunto, em periódicos indexados. Infelizmente, apesar de animadora, essa quantidade de artigos não trouxe um consenso sobre a real eficácia do teste de triagem neonatal para a fibrose cística. A recente e mais completa revisão sobre o assunto ${ }^{1}$ foi realizada para verificar se o uso de screening neonatal poderia prevenir ou reduzir o dano irreversível, ou modificar o curso da fibrose cística, e concluiu que não existem evidências de benefícios na triagem neonatal para a fibrose cística. Ou seja, entre pacientes fibrocísticos que foram submetidos a screening neonatal e aqueles que tiveram diagnóstico precoce, a evolução foi a mesma. Eles recomendam, então, que sejam realizados mais estudos para pesquisar a eficácia do screening neonatal para a fibrose cística. Embora o objetivo dos screenings, para a maioria das doenças, seja reduzir a mortalidade na população investigada pelo tratamento precoce dos casos descobertos ${ }^{2,3}$, ou chamar a atenção para sinais da doença antes dos sintomas aparecerem, esse fato não tem modificado significativamente a evolução da fibrose cística ${ }^{1}$.

Agora, em janeiro de 2003, o New England Journal of Medicine ${ }^{4}$, em seu editorial, recomenda a triagem neonatal para fibrose cística, mas apoiado em resultados de trabalhos científicos. Foi apenas um comentário.

Também em janeiro de 2003, Boyle ${ }^{1}$ relata que esforços devem ser realizados para diferenciar os resultados econômicos, éticos e funcionais dos screenings e dos diagnósti- cos clínicos precoces. Sabe-se que os procedimentos de screenings têm sido mais utilizados para avaliar a prevalência de determinadas doenças do que para avaliar a evolução da doença.

O diagnóstico precoce, pelo entendimento dos sinais e sintomas, poderá ser tão efetivo e eficaz quanto os testes de screening, dispensando gastos econômicos, conflitos éticos, sociais e culturais e, portanto, até que a ciência prove essas relações, somente o tempo nos mostrará, com evidências científicas, a diferença entre os dois, screening neonatal e diagnóstico precoce, na evolução de pacientes com fibrose cística.

Com o nosso artigo $^{6}$, pretendemos informar ao pediatra a importância de valorizar os sinais e sintomas precoces da fibrose cística para a realização do diagnóstico precoce, atualmente com mediana de 2,4 anos em nosso meio ${ }^{7}$, semelhante à de países do primeiro mundo. Então teremos um bom acompanhamento, tratamento e melhor prognóstico para os pacientes. Acreditamos que com uma adequada formação médica, voltada para a valorização de sinais e sintomas, e não predominantemente para a interpretação de resultados de exames, somado à criação de centros especializados no tratamento da fibrose cística, o que tem acontecido no Brasil, é pouco provável que voltemos a deixar o diagnóstico dessa doença para as parteiras.

Continuamos achando, em sintonia com a literatura médica atual, que o tema triagem neonatal em fibrose cística, por não dispor ainda de métodos com maior sensibilidade e especificidade do que os atualmente existentes, é controverso e deve ser colocado para o pediatra geral com todas as suas características.

\section{Referências bibliográficas}

1. Merelle ME, Nagelkerke AF, Lees CM, Dezateaux C. Newborn screening for cystic fibrosis. Cochrane Database Syst Rev 2001; CD001402.

2. Talleria Orriols JJ, Alonso Ramos MJ, Garrote Adrados JÁ, Fernandez Carvajal I, Blanco Quiros A. Neonatal screening for Cystic Fibrosis. Ann Esp Pediatr 2002; 60-5.

3. Comeau AM, Eaton RB. Successes of newborn screening programs. Science 2002; 295:44-5.

4. Khoury MJ, McCabe LL, McCabe ERB. Population Screening in the age of genomic medicine. N Engl J Med 2003; 348:50-8.

5. Boyle P. Sreening. Eur Respir J 2003; 21 supll 39; 3s-15s.

6. Ribeiro JD, Ribeiro MO, Ribeiro AF. Controvérsias na fibrose cística. J Pediatr (Rio J) 2002; 78:S171-S186.

7. Alvarez AE, Ribeiro AF, Hessel G, Bertuzzo CS, Ribeiro JD. Cystic Fibrosis in the last decade of 20th century in Brazil. Clinical and laboratorial characteristics of 104 patients. European Respiratory Journal 2002; 20: (Suppl. 38) 341s.

\section{Jose Dirceu Ribeiro}

Prof. Assistente Doutor, Dep. Pediatria FCM/Unicamp

\section{Maria Ângela G. de O. Ribeiro}

Fisioterapeuta, Mestre em Farmacologia, Dep. Pediatria FCM/Unicamp Antonio Fernando Ribeiro

Prof. Assistente Doutor, Dep. Pediatria FCM/Unicamp 